\title{
Analytical Development of a One-Line Model for the Analysis of Shoreline Change by Wind Generated Waves
}

\author{
Giuseppe Barbaro, Giovanni Malara, Maria Chiara Martino, Felice Arena* \\ "Mediterranea" University of Reggio Calabria, Department of Mechanics and Materials, Loc. Feo di Vito, 89122, \\ Reggio Calabria, Italy
}

\begin{abstract}
This paper deals with an analytical solution of the shoreline evolution due to random sea waves. The phenomenon of the shoreline change is modeled by means of a one-line theory. The solution is based on the hypotheses that the deviation of the shoreline planform from the general shoreline alignment (x-axis) approaches zero and that a particular relationship between higher order derivatives of the shoreline holds. It is proved that the shoreline evolution is described by a diffusion equation, in which the diffusivity $\mathrm{G}_{1 \mathrm{R}}$ is a function of the sea state and the sediment characteristics. Next, particular attention is dedicated to the longshore diffusivity. Its behaviour is analysed and effects of different spectral shapes and of different breaking depths are investigated. It is shown that the diffusivity assumes both positive and negative values.
\end{abstract}

Keywords: One-line model, shoreline, analytical, sea waves, longshore diffusivity, wave spectrum.

\section{INTRODUCTION}

Long-term evolution of the plan shape of sandy beaches was studied by several authors. The first work was developed by Pelnard-Considèr [1]. He introduced the one-line theory by describing the phenomenon with a diffusion equation. He verified its applicability with laboratory experiments. Bakker [2] described the planform change extending the one-line theory by the use of two lines. The two line theory was further developed by Bakker et al. [3], in which a numerical solution of the governing equations was necessary. LeMéhauté and Soldate [4] presented analytical solutions of linearized shoreline change equation with the spread of a rectangular beach fill. LeMéhauté and Soldate $[5,6]$ developed a numerical model that included the effect of sea level variation, wave refraction and diffraction, and the influence of coastal structures. Hanson and Larson [7] compared analytical and numerical solutions. They verified that to neglect wave refraction was more restrictive then the small angle approximation. Larson et al. [8] introduced a large number of new solutions. The new solutions described shoreline change without coastal structures that are applicable both to natural and artificial beach forms. Also solutions with the effect of coastal structures were presented. Larson et al. [9] presented analytical solutions for shoreline evolution in the vicinity of coastal structures with and without diffraction. They showed that the essential features of the shoreline change may be preserved using an idealization of the influence of coastal structures. One-line models were used also to predict long term planform evolution of beach nourishment (e.g. Dean [10, 11]; Hanson [12]). Limits of classical oneline models have been analysed. Ashton et al. [13] and

*Address correspondence to this author at the "Mediterranea" University of Reggio Calabria, Department of Mechanics and Materials, Loc. Feo di Vito, 89122, Reggio Calabria, Italy; Tel. +39 (0)965 875292; +39 3355387968; Fax:+39(0)965 875201; E-mail: arena@unirc.it
Falqués [14] showed that the diffusivity can be negative. Falqués and Calvete [15] proposed an extended one-line model with two main improvements: the curvature of the coastline features is accounted for and the coastline features are assumed to extend offshore as a bathymetric perturbation up to a finite distance.

$\mathrm{N}$-line models were developed by Hanson and Larson [16], and Dabees and Kamphuis [17], which presented, respectively, the INLINE model and the NLINE model. N-line models were more detailed and time consuming than oneline models, but the difficulty to specify realistic relations for the cross-shore sediment transport and for the cross-shore distribution of the longshore sediment transport limited its applicability (Hanson et al. [18]).

Hybrid models were developed to combine longshore and cross-shore models. For example, Larson et al. [19] developed 3DBEACH model, in which GENESIS one-line model is linked to SBEACH beach profile evolution model of Larson and Kraus [20].

This paper deals with the derivation of a new analytic solution for the analysis of shoreline change in the context of one-line models. A new expression for the diffusivity, in the following named $G_{I R}$, is proposed. It overcomes limits of periodic wave theory by considering random sea waves and taking into account wave spectrum.

\section{PROBLEM FORMULATION}

\section{Governing Equation}

Let us consider a Cartesian coordinate system (Fig. 1), with the $x$-axis along the shoreline, the $y$-axis orthogonal to it and landward oriented, and the vertical $z$-axis with origin at the mean water level. The axis $\xi$ is orthogonal to the shoreline and is seaward oriented (then $\xi$ is opposite to the $y$-axis) and $b$ defines the water depth at breaking. 


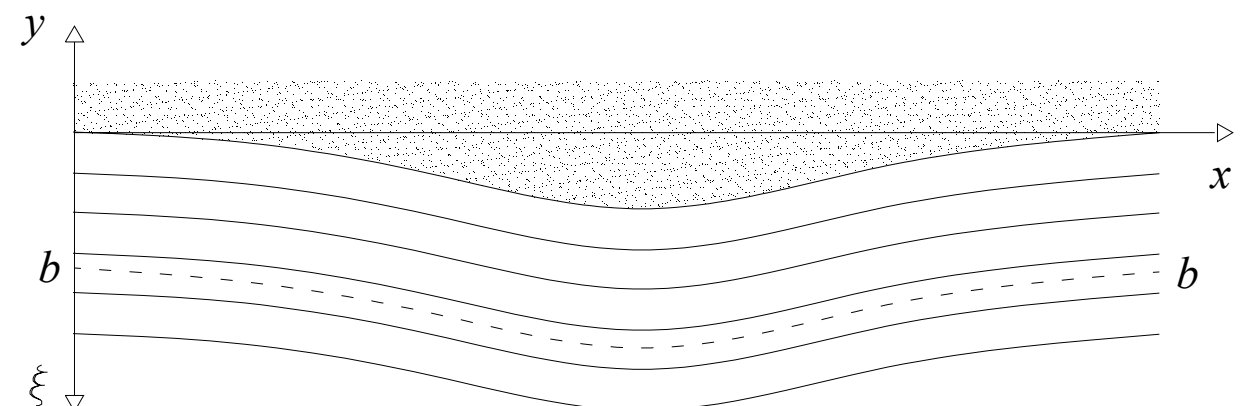

Fig. (1). Reference frame; vertical $z$-axis has origin at the mean water level; $b$ denotes the breaking depth.

The rate of change of the shoreline in the time domain is expressed by the equation of solid material conservation [1]:

$$
\frac{\partial \xi}{\partial t}=- \text { const } \frac{\partial Q}{\partial x}
$$

where $Q$ is the volumetric amount of solid material which the sea is generally capable of moving.

The sign of the left hand side of eq. (1) defines the shoreline behavior: if $\partial \xi / \partial t>0$ there is a beach accretion; if $\partial \xi / \partial t=0$ the beach is stable; if $\partial \xi / \partial t<0$ there is a beach erosion.

\section{Longshore Sediment Transport by Random Sea Waves}

The longshore sediment transport depends upon both the sediment and the radiation stress tensor [21, 22], which is defined as:

$$
R_{x y} \equiv \rho \lim _{\tau \rightarrow \infty} \frac{1}{\tau} \int_{0}^{\tau} \int_{-d}^{\eta} \frac{\partial \varphi}{\partial y} \frac{\partial \varphi}{\partial x} d z d t
$$

where $\rho$ is the water density and $\varphi$ the velocity potential.

Let us define the radiation stress tensor in the context of the theory of wind-generated waves, formulated by LonguetHiggins [23] and Phillips [24], which represents a random sea state as a sum of a very large number $N$ of periodic components with infinitesimal amplitudes $a_{i}$, frequencies, $\omega_{i}$, different from each other, and random phase angles $\varepsilon_{i}$ uniformly distributed over the interval $[0,2 \pi]$ and stochastically independent from each other.

Under these assumptions, the linear water surface and velocity potential processes are stationary Gaussian processes in time domain. The expression of the potential in a random three-dimensional sea state is equal to

$\varphi(x, y, z, t)$

$=g \sum_{i=1}^{N} a_{i} \omega_{i}^{-1} \frac{\cosh \left[k_{i}(d+z)\right]}{\cosh \left(k_{i} d\right)} \sin \left(k_{i} x \sin \vartheta_{i}+k_{i} y \cos \vartheta_{i}-\omega_{i} t+\varepsilon_{i}\right)$

where $g$ is the acceleration due to gravity, $\vartheta_{i}$ is the angle which the propagation direction of the $i$ th component makes with the $y$-axis. The wave number $k_{i}$ is given by

$$
k_{i} \tanh \left(k_{i} d\right)=\omega_{i}^{2} / g
$$

with $d$ the water depth.
The free surface displacement is:

$$
\eta(x, y, t)=\sum_{i=1}^{N} a_{i} \cos \left(k_{i} x \sin \vartheta_{i}+k_{i} y \cos \vartheta_{i}-\omega_{i} t+\varepsilon_{i}\right)
$$

with variance

$$
\sigma^{2}=\int_{0}^{\infty} \int_{0}^{2 \pi} S_{0}(\omega, \vartheta) d \vartheta \mathrm{d} \omega
$$

where $S_{0}(\omega, \vartheta)$ is the directional wave spectrum of the surface displacement in deep water, defined as

$$
\begin{aligned}
& \quad S_{0}(\omega, \vartheta) \delta \vartheta \delta \omega=\frac{1}{2} \sum_{i} a_{i}^{2} \text { for } i \text { such that } \omega<\omega_{i}<\omega+\delta \omega, \\
& \vartheta<\vartheta_{i}<\vartheta+d \vartheta
\end{aligned}
$$

In this context, substituting (3) in (2), the radiation stress tensor has the following expression:

$$
R_{x y}=\frac{1}{2} \rho g \sum_{i=1}^{N} \frac{1}{2} a_{i}^{2} \sin \vartheta_{i} \cos \vartheta_{i}\left[\frac{\sinh \left(2 k_{i} d\right)+2 k_{i} d}{\sinh \left(2 k_{i} d\right)}\right]
$$

The formula for the longshore transport rate is a function of the sediment characteristics and the radiation stress tensor and is expressed as (see e.g. [25]):

$$
Q=W R_{x y} \sqrt{g d_{b}}
$$

where $d_{b}$ is the breaking depth, $W$ is defined as:

$W \equiv \frac{K}{\mu} /\left[\left(\frac{\gamma_{s}}{\gamma_{a}}-1\right)(1-p)\right]$

with $K$ depending the size of the sand, as shown by Komar and Inman [26], Dean [27]; $\mu$ is the friction coefficient, $p$ the sediment porosity, $\gamma_{a}$ is the specific weight of the water and $\gamma_{s}$ the specific weight of the sand.

It is then defined the longshore sediment transport as: 


$$
Q=\frac{1}{4} W \sqrt{g d_{b}} \sum_{i=1}^{N} \frac{1}{2} a_{i}^{2} \sin \left(2 \vartheta_{i}\right)\left[1+\frac{2 k_{i} d}{\sinh \left(2 k_{i} d\right)}\right]
$$

\section{Derivation of the Diffusion Equation}

The equation of sediment conservation [eq. (1)] is expressed as a function of the shoreline $\xi$, by substituting the previous expression for the longshore transport [eq. (4)]. The main difficulty is the estimation of the derivative of $Q$ with respect to $x$.

In this context the following assumption is introduced:

$$
\frac{\partial \xi}{\partial x} \rightarrow 0
$$

In this way amplitudes, breaking depth and wave angles are expressed as the sum of a contribution estimated in the case of $x$-parallel contour lines and of small variations, to account for the variations of the shoreline. Usually, breaking depth and amplitude variations are neglected [25], because these are infinitesimal. The limit of this approach is that it doesn't account for the variations of the longshore transport, in fact, even if $\partial Q / \partial x$ is infinitesimal, it cannot be said that these variations are negligible. Moreover, to neglect the effect of the shoreline curvature, it is introduced the following assumption [25]:

$$
\left.\left|\Delta y_{0}\right| \frac{\partial^{n+1} \xi}{\partial x^{n+1}}\right|_{\max }<\left|\frac{\partial^{n} \xi}{\partial x^{n}}\right|_{\max } \text { for } n=1,2,3, \ldots
$$

Given these hypotheses, a straight coastline, with bathymetric lines parallel to the shoreline, is considered. If $\vartheta_{i b}$ is the angle that the direction of propagation of the $i$ th component forms with the $y$-axis at breaking, the angle formed with the local tangent is $\vartheta_{i b}+\delta \vartheta_{i b}$. The variation in incline thus carries the variation in the breaking conditions, in other words: breaking depth is $d_{i b}+\delta d_{i b}$; wave width on the breaker line is $a_{i b}+\delta a_{i b}$.

In eq. (4) each term is expanded to the first order in a Taylor series. By considering that:

$$
\delta \vartheta_{i b}=-\frac{\partial \xi}{\partial x}
$$

and assuming that at the breaking depth:

$$
\frac{H_{s b}}{d_{b}}=\frac{H_{s b}+\delta H_{s b}}{d_{b}+\delta d_{b}}=0.8
$$

where $H_{s b}$ is the significant wave height at the breaking depth, the following diffusion equation is derived:

$$
\frac{\partial \xi}{\partial t}=G_{1 R} \frac{\partial^{2} \xi}{\partial x^{2}}
$$

where:
$G_{1 R}=\operatorname{const} \frac{W}{4} \sqrt{g q_{\phi}} \sum_{i=1}^{7} I_{i}$

In eq. (6) terms $I_{i}$ are defined as:

$$
\begin{aligned}
& I_{1}=2 \int_{0}^{\infty} \int_{0}^{2 \pi} \mathrm{S}_{\mathrm{b}}(\omega, \vartheta) \cos \left(2 \vartheta_{b}\right) d \vartheta d \omega \\
& I_{2}=2 \int_{0}^{\infty} \int_{0}^{2 \pi} \mathrm{S}_{\mathrm{b}}(\omega, \vartheta) \sin \left(2 \vartheta_{b}\right) K_{a}(\omega, \vartheta) d \vartheta d \omega \\
& I_{3}=\frac{d_{b}^{-1}}{2} K_{\sigma} \int_{0}^{\infty} \int_{0}^{2 \pi} \mathrm{S}_{\mathrm{b}}(\omega, \vartheta) \sin \left(2 \vartheta_{b}\right) d \vartheta d \omega \\
& I_{4}=2 \int_{0}^{\infty} \int_{0}^{2 \pi} \mathrm{S}_{\mathrm{b}}(\omega, \vartheta) \cos \left(2 \vartheta_{b}\right) \frac{2 k_{b} d_{b}}{\sinh \left(2 k_{b} d_{b}\right)} d \vartheta d \omega \\
& I_{5}=2 \int_{0}^{\infty} \int_{0}^{2 \pi} \mathrm{S}_{\mathrm{b}}(\omega, \vartheta) K_{a}(\omega, \vartheta) \sin \left(2 \vartheta_{b}\right) \frac{2 k_{b} d_{b}}{\sinh \left(2 k_{b} d_{b}\right)} d \vartheta d \omega \\
& I_{7}=d_{b}^{-1} K_{\sigma} \int_{0}^{\infty} \int_{0} \mathrm{~S}_{\mathrm{b}}(\omega, \vartheta) \sin \left(2 \vartheta_{b}\right)\left[1-\frac{2 k_{b} d_{b}}{\sinh \left(2 k_{b} d_{b}\right)}\right] . \\
& I_{6}=\frac{2 k_{b} d_{b}}{2} K_{\sigma} \int_{0} \int_{0} \mathrm{~S}_{\mathrm{b}}(\omega, \vartheta) \sin \left(2 \vartheta_{b}\right) \frac{2 k_{b} d_{b}}{\sinh \left(2 k_{b} d_{b}\right)} d \vartheta d \omega \\
& \left.k_{b}\right)
\end{aligned}
$$

where the subscript $b$ denotes breaking conditions, and it has been defined as:

$$
\begin{gathered}
K_{\sigma}=\frac{\left.5 \frac{\partial \sigma}{\partial \vartheta}\right|_{d=d_{b}}}{1-\left.5 \frac{\partial \sigma}{\partial d}\right|_{d=d_{b}}} \\
K_{a}(\omega, \vartheta)=\left.\frac{1}{a_{i b}} \frac{\partial a_{i}}{\partial d}\right|_{d=d_{b}} K_{\delta}+\left.\frac{1}{a_{i b}} \frac{\partial a_{i}}{\partial \vartheta}\right|_{d=d_{b}}
\end{gathered}
$$

with $\sigma$ the standard deviation of the free surface displacement.

Eq. (5) is known as diffusion equation and is formally identical to the equation describing heat conduction in solids. Many authors worked on this topic, therefore, by considering the analogies between the initial and boundary conditions of the shoreline evolution and the heat conduction, analytical 


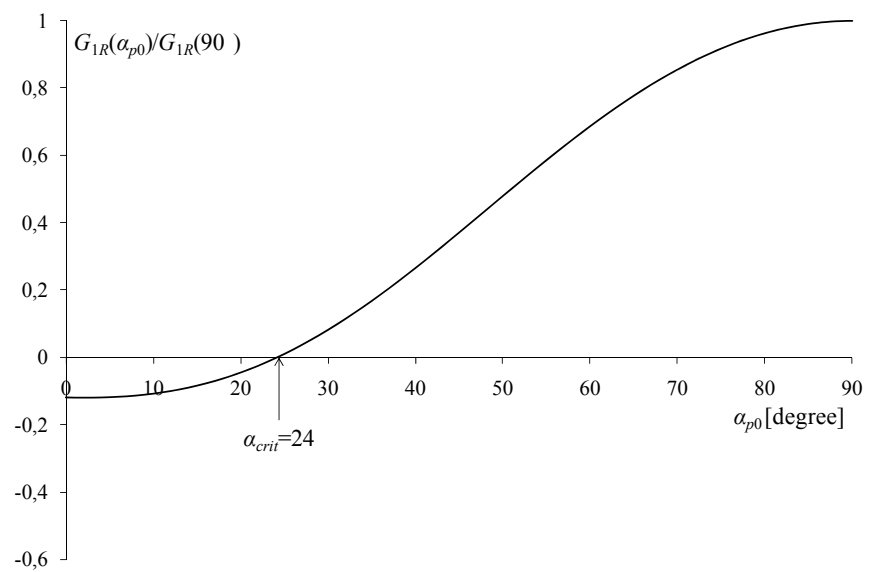

Fig. (2). Diffusivity change as a function of the angle that the dominant direction forms offshore with the $x$-axis. The following characteristics have been assumed: $d_{b} / L_{p 0}=0.2$, Pierson - Moskowitz frequency spectrum, directional spreading function of Mitsuyasu et al.

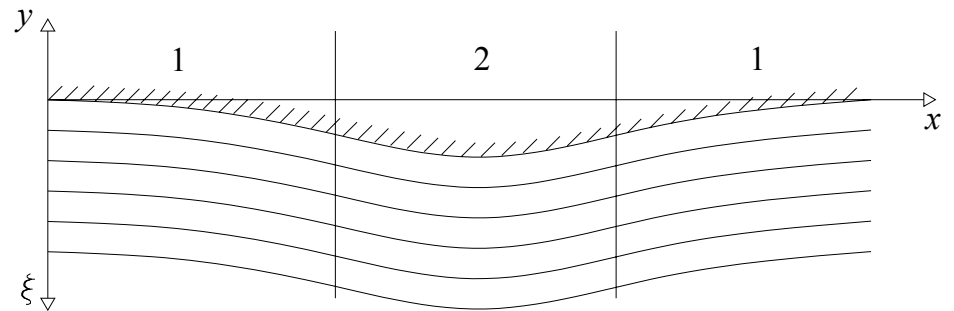

Fig. (3). Sub regions: zone 1 is characterized by a positive curvature, zone 2 is characterized by a negative curvature.

solutions can be generated. The coefficient $G_{l R}$ [eq. (6)] can be interpreted as a diffusion coefficient with dimensions of length squared over time.

\section{On Diffusivity Computation}

Eq. (6) requires to fix a spectral shape in order to estimate all integrals, at the breaking depth. In the following a deep water spectrum is assumed and the shoaling-refraction equation for random waves [25,28] is used to estimate the diffusivity. In this context (7) and (8) are related to the fixed spectrum. Following [28] amplitudes at the breaking depth are estimated as:

$a_{i b}=a_{i 0} C_{S}(\omega) C_{R}(\omega, \vartheta)$

being $a_{i 0}$ the wave amplitude at infinite depth, $C_{S}(\omega)$ the shoaling coefficient and $C_{R}(\omega, \vartheta)$ the refraction coefficient. This allows to estimate each term in (8) as:

$$
\begin{aligned}
& \left.\frac{\partial a_{i}}{\partial d}\right|_{d=d_{b}}=a_{i 0}\left\{\frac{\partial C_{S}(\omega)}{\partial d} C_{R}(\omega, \vartheta)+C_{S}(\omega) \frac{\partial C_{R}(\omega, \vartheta)}{\partial d}\right\} \\
& \left.\frac{\partial a_{i}}{\partial \vartheta}\right|_{d=d_{b}}=a_{i 0} C_{S}(\omega) \frac{\partial C_{R}(\omega, \vartheta)}{\partial \vartheta}
\end{aligned}
$$

while in (7):

$$
\begin{aligned}
& \left.\frac{\partial \sigma}{\partial \vartheta}\right|_{d=d_{b}}=\left(\int_{0}^{\infty} \int_{0}^{2 \pi} S_{b}(\omega, \vartheta) d \vartheta d \omega\right)^{-1 / 2} \cdot \\
& \cdot \int_{0}^{\infty} \int_{0}^{2 \pi} S_{0}(\omega, \vartheta) C_{S}^{2}(\omega, \vartheta) C_{R}(\omega) \frac{\partial C_{R}(\omega, \vartheta)}{\partial \vartheta} d \vartheta d \omega \\
& \left.\frac{\partial \sigma}{\partial d}\right|_{d=d_{b}}=\left(\int_{0}^{\infty} \int_{0}^{2 \pi} S_{b}(\omega, \vartheta) d \vartheta d \omega\right)^{-1 / 2} \cdot \\
& \cdot \int_{0}^{\infty} \int_{0}^{2 \pi} S_{0}(\omega, \vartheta) C_{R}(\omega, \vartheta) C_{s}(\omega)\left[C_{R}(\omega, \vartheta) \frac{\partial C_{s}(\omega)}{\partial d}+C_{s}(\omega) \frac{\partial C_{R}(\omega, \vartheta)}{\partial d}\right] d \vartheta d \omega
\end{aligned}
$$

\section{APPLICATIONS}

\section{Diffusivity Behavior}

Fig. (2) shows the values of $G_{l R}$, calculated by means of eq. (6), as a function of $\alpha_{p 0}$, which is the angle that the dominant direction forms with the $x$-axis in deep water. It has been assumed $d_{b} / L_{p 0}=0.2, L_{p 0}$ being the dominant wave length at infinite depth, a Pierson - Moskowitz frequency spectrum [29] and a directional spreading function of Mitsuyasu et al. [30]. The analysis is limited to the range $\left[0,90^{\circ}\right]$ of wave direction, being diffusivity symmetric with respect to $\alpha_{p 0}=90^{\circ}$. Fig. (2) reveals that the diffusivity has both positive and negative values. It is clearly positive after a particular angle, defined critical angle $\alpha_{c r i t}$. The critical angle 


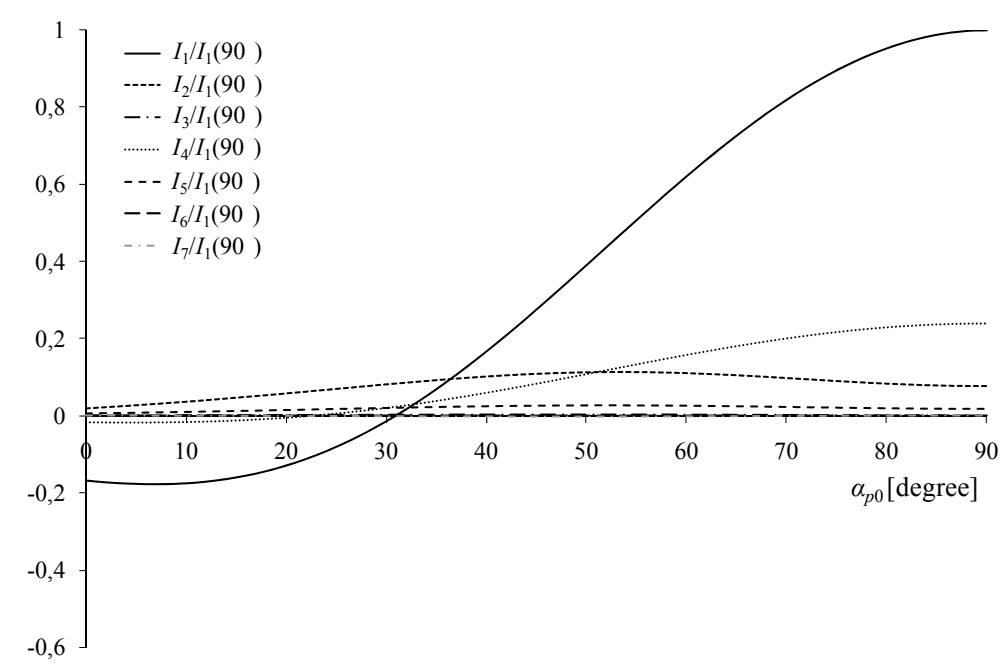

Fig. (4). Terms of eq. (6). The following characteristics have been assumed: $d_{b} / L_{p 0}=0.2$, Pierson - Moskowitz frequency spectrum, directional spreading function of Mitsuyasu et al.

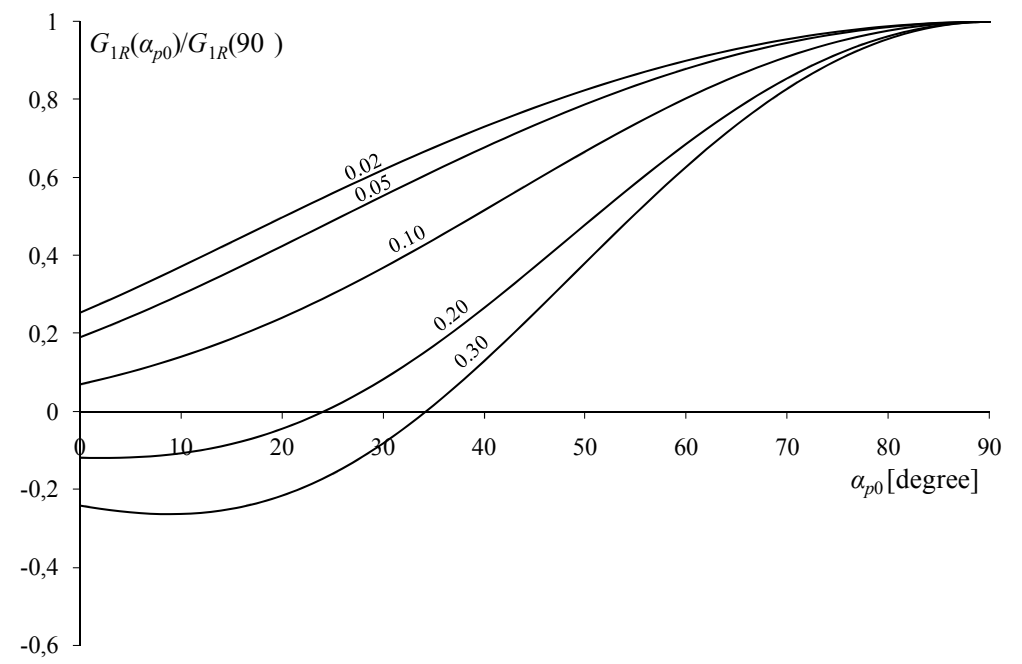

Fig. (5). Diffusivity change for different relative depths $d_{b} / L_{p 0}$. To each curve is associated a value of $d_{b} / L_{p 0}$; the frequency spectrum is Pierson - Moskowitz, with directional spreading function of Mitsuyasu et al.

is defined as the angle which corresponds to a zero value of the diffusivity.

Fig. (3) shows how (5) can be used to predict the shoreline evolution. Zone 1 has positive curvature, while zone 2 has negative curvature. Then, if diffusivity is positive zone 1 is advancing and zone 2 is eroding; vice versa for a negative diffusivity. If the diffusivity is zero, then the shoreline is stable.

Fig. (4) shows the contribution of each term in (6) to the diffusivity. It shows that the first term in (6) captures the general behavior of the diffusivity. It is a simple way to check if it assumes both positive and negative values, but for the applicability of eq. (5) more terms are necessary.

\section{Effect of the Relative Breaking Depth}

Fig. (5) shows the effect of the relative water depth. It has been assumed a Pierson - Moskowitz frequency spectrum and a directional spreading function of Mitsuyasu et al. The following breaking depths have been considered: $d_{b} / L_{p 0}$ $=0.02,0.05,0.10,0.20$ and 0.30 .
The magnitude of the longshore diffusivity decreases as breaking depth becomes smaller and smaller. For larger of the breaking depth, the diffusivity can be negative for wave direction smaller than the critical angle, which are $24^{\circ}$ and $34^{\circ}$ for $d_{b} / L_{p 0}=0.2$ and 0.3 respectively. In general, the critical angle increases with the relative water depth.

\section{Influence of the Directional Spectrum}

Fig. (6) shows a comparison assuming two different frequency spectra. In both cases it has been assumed a directional spreading function of Mitsuyasu et al. and $d_{b} / L_{p 0}=0.02$. Then a Pierson-Moskowitz (continuous line) and a mean JONSWAP spectrum [31] (dotted line) have been considered. The normalized functions are almost indistinguishable, but it has to be pointed out that the longshore diffusivity, at $\alpha_{p 0}=90^{\circ}$, varies with the bandwidth of the spectrum. The diffusivity decreases as narrower the spectrum is. At this purpose, the values of the diffusivity at $\alpha_{p 0}=90^{\circ}$ are estimated. The estimation shows that, for fixed sediment characteristics, the diffusivity is: 


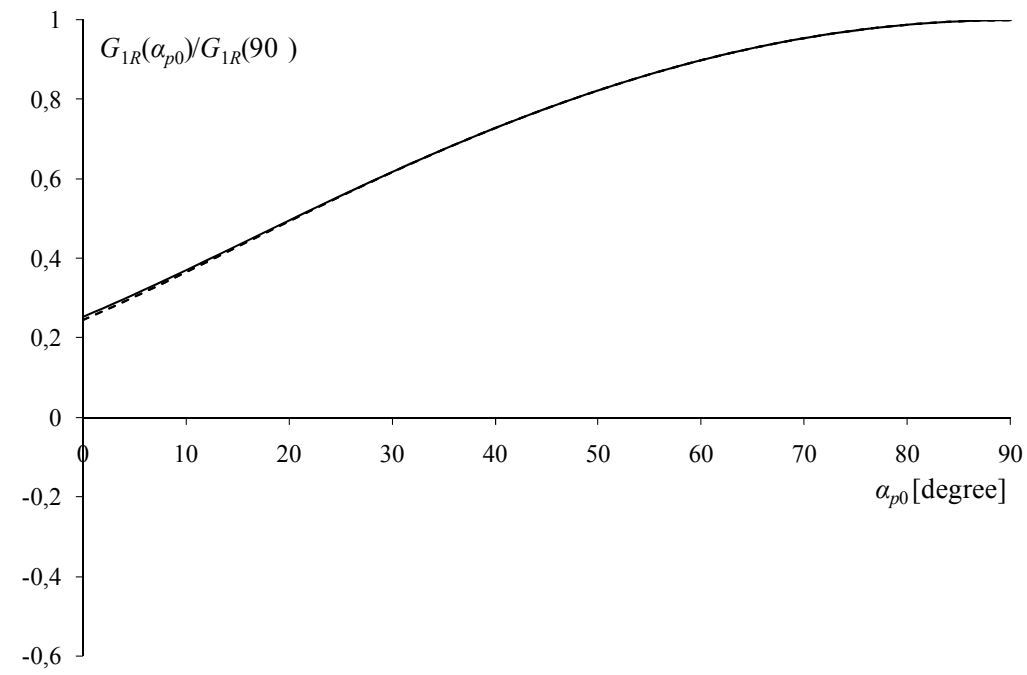

Fig. (6). Diffusivity change for different frequency spectra. The following characteristics have been assumed: $d_{b} / L_{p 0}=0.02$, directional spreading function of Mitsuyasu et al., Pierson-Moskovitz spectrum (continuous line) and a JONSWAP spectrum (dotted line).

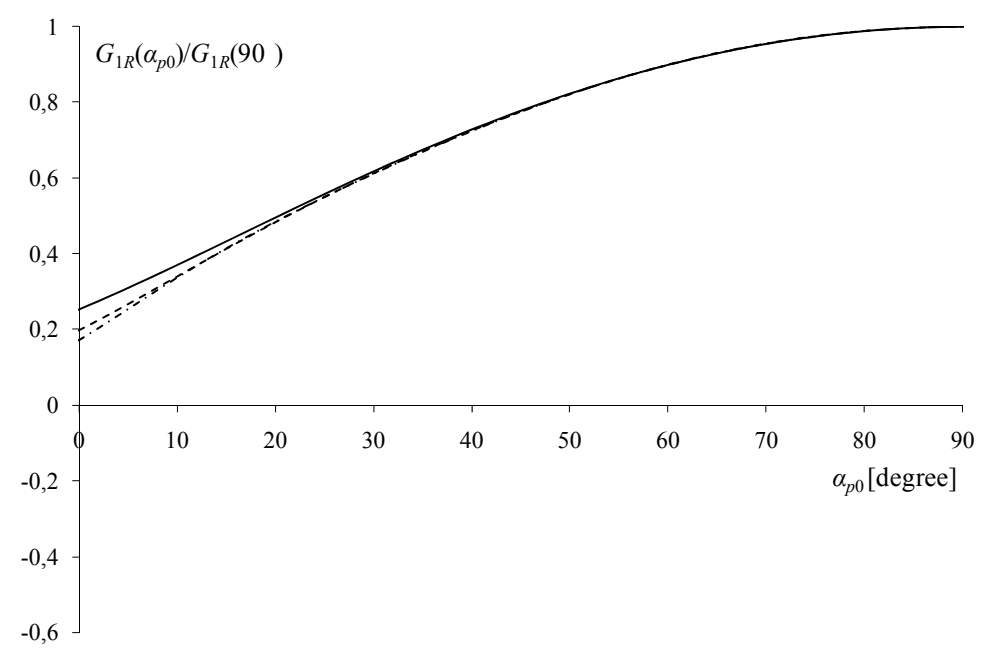

Fig. (7). Diffusivity change for different directional spreading functions. The following characteristics have been assumed: $d_{b} / L_{p 0}=0.02$, Pierson - Moskowitz frequency spectrum. In both cases a cosine power directional spreading function has been used. The continuous line corresponds to $n_{p}=20$, the dotted line to $n_{p}=50$, the point-line curve to long crested waves.

$\frac{G_{1 R}\left(90^{\circ}\right)}{\text { const } \cdot W}=7.63 \mathrm{~m}^{3} / \mathrm{s}$, for a Pierson - Moskowitz frequency spectrum

and

$\frac{G_{1 R}\left(90^{\circ}\right)}{\text { const } \cdot W}=7.04 \mathrm{~m}^{3} / \mathrm{s}$, for a mean JONSWAP frequency spectrum.

Fig. (7) shows the effect of the directional spreading function. For the analysis a cosine power function has been assumed:

$$
D(\vartheta ; \omega)=K(n) \cos ^{2 n}\left[\frac{1}{2}(\vartheta-\bar{\vartheta})\right] \text { with } n=n(\omega)
$$

where the normalizing factor is:

$$
K(n)=\left[\int_{0}^{2 \pi} \cos ^{2 n} \frac{\vartheta}{2} d \vartheta\right]^{-1}
$$

and the parameter $n$ is:

$$
n= \begin{cases}n_{p}\left(\omega / \omega_{p}\right)^{5} & \text { for } \omega \leq \omega_{p} \\ n_{p}\left(\omega / \omega_{p}\right)^{-2.5} & \text { for } \omega>\omega_{p}\end{cases}
$$

$n_{p}$ being a function of fetch and wind velocity.

In Fig. (7) the continuous line is related to the case $n_{p}=20$, the dotted line to $n_{p}=50$ and a point-line curve is adopted for a long crested wave. Only for $\alpha_{p 0}<30^{\circ}$ the effect of the directional spreading function is meaningful. Larger is $n_{p}$, lower values assumes the diffusivity.

A comparison is carried out considering a PiersonMoskowitz frequency spectrum and a narrow-band spectrum (Fig. 8). The normalized functions have the same characteristics as in Fig. (7), but the values are a function of the spectrum bandwidth as observed for Fig. (6). 


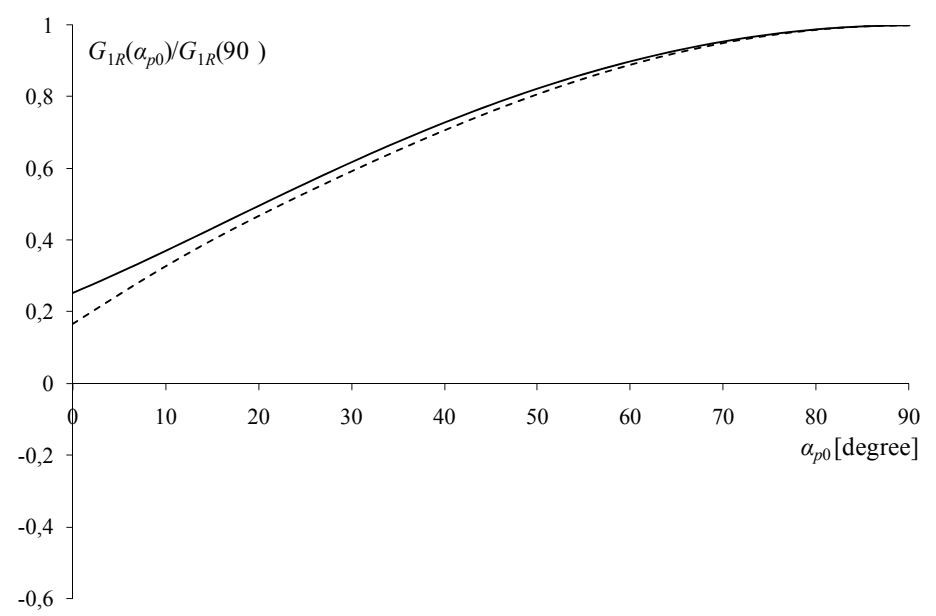

Fig. (8). Comparison of diffusivity for random wind-generated waves with a Pierson - Moskowitz frequency spectrum (continuous line) and with a narrow band spectrum (dotted line). The following characteristics have been assumed: $d_{b} / L_{p 0}=0.02$, directional spreading function of Mitsuyasu et al.

\section{CONCLUSIONS}

In this paper a new analytical solution for the shoreline change has been proposed. It extends the Boccotti's [25] solution for periodic waves in the context of random windgenerated waves. The governing equation is expressed in the form of a diffusion equation and the expression of the diffusivity $G_{1 R}$ has been obtained for a random sea state. It has been shown as it is possible to estimate the shoreline change starting from the diffusivity and the curvature of the shoreline.

The change of $G_{1 R}$ has been analyzed. It has been verified that the diffusivity increases with $\alpha_{p 0}$, for $\alpha_{p 0}$ between 0 and $90^{\circ}, \alpha_{p 0}$ being the angle that the dominant direction of the wave motion forms with the $x$-axis. The effect of the relative breaking depth has been investigated. It has been shown as the effect of an increased relative breaking depth is to decrease the diffusivity. The main consequence is that the diffusivity can assume negative values for large wave breaking depths, $d_{b} / L_{p 0}$, greater than 0.15 with wave direction $\alpha_{p 0}$ smaller than the critical angle.

Effects of different spectral shapes have been investigated. Two elements can be emphasized: the longshore diffusivity decreases as narrower the wave spectrum is, both in the frequency domain and in the direction one. Then, in a three-dimensional wave field, the longshore diffusivity is smaller with respect to a narrow spectrum, for a fixed value of the zeroth moment of the spectrum.

\section{REFERENCES}

[1] R. Pelnard-Considère, "Essai de theorie de l'Evolution des Formes de Rivage en Plages de Sable et de Galets", In: $4^{\text {th }}$ Journees de l'Hydraulique, Les Energies de la Mer, Question III, Rapport No. $1,1956$.

[2] W. T. Bakker, "The dynamics of a coast with a groin system", In: Proc. $11^{\text {th }}$ Coast. Engrg. Conf., ASCE, 1969, pp. 492-517.

[3] W. T. Bakker, E.H.J. Klein-Breteler, and A. Roos, "The dynamics of a coast with a groin system", In: Proc. $12^{\text {th }}$ Coast. Engrg. Conf., ASCE, 1971, pp. 1001-1020.

[4] B. LeMéhauté, and M. Soldate. "Mathematical modelling of shoreline evolution", CERC Mescellaneous Rep. No. 77-10, USAEWES, Coast. Engrg. Res. Ctr., 1977.
[5] B. LeMéhauté, and M. Soldate. "Mathematical modelling of shoreline evolution", Rep. No. TC-831, Tetra Tech. Inc., 1978.

[6] B. LeMéhauté, and M. Soldate. "Mathematical modelling of shoreline evolution", In: Proc. $16^{\text {th }}$ Coast. Engrg. Conf., ASCE, 1979, pp. 1163-1179.

[7] H. Hanson, and M. Larson, "Comparison of analytic and numerical solutions of the one-line model of shoreline change", In: Proc. Coast. Sed. '87, ASCE, 1987, pp. 500-514.

[8] M. Larson, H. Hanson, and N. C. Kraus. "Analytical solutions of the one-line model of shoreline change", Tech. Rep. CERC-87-15, USAE-WES, Coast. Engrg. Rest. Ctr. 1987.

[9] M. Larson, H. Hanson, and N. C. Kraus. "Analytical solutions of one-line model for shoreline change near coastal structures", $\mathrm{J}$. $\mathrm{Wa}$ terway, Port, Coastal, Ocean Eng. vol. 123, pp. 180-191, July/August 1997.

[10] R. G. Dean. "Principles of beach nourishment", In: Komar, P. D. (Ed.), CRC Handbook Coastal Processes and Erosion, CRC Press; Boca Raton, pp. 217-232, 1983.

[11] R. G. Dean. "Beach nourishment performance: planform considerations", Shore Beach, vol. 64, pp. 36-39, July 1996.

[12] H. Hanson. "GENESIS - A generalized shoreline change numerical model", J. Coastal Res., vol. 5, pp. 1-27, 1988.

[13] A. Ashton, A. B. Murray, and O. Arnoult. "Formation of coastline features by large-scale instabilities induced by high-angle waves", Nature, vol. 414, pp. 296-300, 2001.

[14] A. Falqués. "On the diffusivity in coastline dynamics". Geophys. Res. Lett., vol. 30, pp. 2119, 2003.

[15] A. Falqués, and D. Calvete "Large-scale dynamics of sandy coastlines: Diffusivity and instability", J. Geophys. Res., vol. 110, pp. C03007, 2005 .

[16] H. Hanson, and M. Larson. "Simulating shoreline evolution using a new type of N-line model". In: Proc. 27 ${ }^{\text {th }}$ Coastal Engineering Conference, ASCE, 2000, pp. 2808-2821.

[17] M. A. Dabees, and J. W. Kamphuis. "Nline: efficient modelling of 3-D beach change". In: Proc. $27^{\text {th }}$ Coastal Engineering Conference, ASCE, 2000, pp. 2700-2713.

[18] H. Hanson, M. Aarninkhof, M. Capobianco, J. A. Jiménez, M. Larson, R. J. Nicholls, N. G. Plant, H. N. Southgate, H. J. Steetzel, M. J. F. Stive, and H. J. de Vriend. "Modelling of coastal evolution on yearly to decadal time scales." J. Coastal Res., vol. 19, pp. 790$811,2003$.

[19] M. Larson, N. C. Kraus, H. Hanson. "Decoupled numerical model of three-dimensional beach range." Proc. $22^{\text {nd }}$ Coastal Engineering Conference, ASCE, 1990, pp. 2173-2185.

[20] M. Larson, N. C. Kraus. "SBEACH: Numerical model for simulating storm induced beach change." Technical Report CERC-89-9. US Army Corps of Engineers, Waterways Experiment Station, Vicksburg, MS, USA, 1989 
[21] M. S. Longuet-Higgins, R. W. Stewart. "Changes in the form of short gravity waves on long waves and tidal currents", J. Fluid Mech., vol. 8, pp. 565-583, 1960.

[22] M. S. Longuet-Higgins, R. W. Stewart. "The changes in amplitude of short gravity waves on steady, non-uniform currents", J. Fluid Mech., vol. 10, pp. 529-583, 1961.

[23] M. S. Longuet-Higgins. "The effects of non-linearities on statistical distributions in the theory of sea waves", J. Fluid Mech., vol. 17, pp. 459-480, 1963.

[24] O. M. Phillips. "The theory of wind-generated waves", $A d v . H y-$ drosci., vol. 4, pp. 119-149, 1967.

[25] P. Boccotti, Wave Mechanics for Ocean Engineering. Oxford: Elsevier Science, 2000.

[26] P. D., Komar, D. L. Inman. "Longshore sand transport on the beaches", J. Geophys. Res. vol. 75, pp. 5914-5927, 1970.

[27] R. G. Dean. "Beach nourishment: Design Principles", In: Proc. Short Course attached to the $23^{\circ}$ Conf. Coastal Eng., 1992, pp. 301-349.
[28] P. Boccotti. "Refraction, reflection and diffraction of irregular gravity waves", Excerpta Ital. Contrib Field Hydraulic Eng., vol. 3, pp. $47-88,1988$

[29] W. J. Pierson, L. Moskowitz, "A proposed spectral form for fully developed waves based on the similarity of S. A. Kitaigorodskii", J. Geophys. Res., vol. 69, pp. 5181-5190, 1964.

[30] H. Mitsuyasu, F. Tasai, T. Suhara, S. Mizuno, M. Ohkusu, T. Honda, K. Rikiishi, "Observation of directional spectrum of ocean waves using a clover-leaf buoy", J. Phys. Oceanogr., vol. 5, pp. 750-760, 1975 .

[31] K. Hasselmann, T.P. Barnett, E. Bouws, H. Carlson, D.E. Cartwright, K. Enke, J. A. Ewing, H. Gienapp, D.E. Hasselmann, P. Kruseman, A. Meerburg, P. Mller, D.J. Olbers, K. Richter, W. Sell, $\mathrm{H}$. Walden. "Measurements of wind wave growth and swell decay during the Joint North Sea Wave Project (JONSWAP)", Deut. Hydrogr. Zeit. vol. A8, pp. 1-95, 1973.

(C) Barbaro et al.; Licensee Bentham Open.

This is an open access article licensed under the terms of the Creative Commons Attribution Non-Commercial License (http://creativecommons.org/licenses/by-nc/3.0/) which permits unrestricted, non-commercial use, distribution and reproduction in any medium, provided the work is properly cited. 